\title{
Additional Pathologic Findings
}

National Cancer Institute

\section{Source}

National Cancer Institute. Additional Pathologic Findings. NCI Thesaurus. Code C158809.

A section header that includes additional pathologic findings. 